\title{
Loïc Wacquant: Karşılaştırmalı Bir Kent Sosyolojisinin Ana Hatları*
}

*

\author{
Tom Slater \\ Edinburgh Üniversitesi
}

Çeviren: Müge Güvenç Akçaoğlu

\section{Öz}

Sosyal bilimlerin iki devinin, Pierre Bourdieu ve William Julius'un üretken öğrencisi Loïc Wacquant, kent çalışmalarına, etkisi kentlerden çok daha öteye uzanan, çeşitli ve özgün katkllar sunan disiplinler arası bir sosyologdur. Beden sosyolojisi, ceza devleti, etnik-ırksal tahakküm ve toplum kuramı üzerine kurucu nitelikteki yazıları iki düzine dile çevrilmiş ve çeşitli disiplinlerdeki tartışmaları tetiklemiştir. Kent araştırmacıları içerisinde en çok karşılaştırmalı incelemeleri ve ilerlemiş marjinallik ve bölgesel damgalama kavramsallaştırması ile bilinmektedir. Ayrıca yoksulluğun cezalandırılması üzerine tezi ve başa çıkılması zor getto problemini yeniden ele alışı da yaygın bir biçimde okunmaktadır. Çalışmaları, epistemolojik kopuşun ve teorik inşanın aracı olarak yoğun alan araştırmasına dayalıdır. Wacquant'ın marjinalliğin üreticisi olarak devletin rolü, kentlerdeki mülksüzleştirmenin üretilmesinde sembolik yapıların ağırlı̆̆l, kuram, etnografya ve karşılaştırmalı çalışmalar konularındaki vurgusu bilhassa ögretici ve kışkırtıci olmuştur.

Wacquant, Kaliforniya Üniversitesi, Berkeley'de Sosyoloji profesörü ve Paris'te Avrupa Sosyoloji ve Siyaset Bilimi Merkezi'nde (Centre de Européen de Sociologie et de Science Politique) araştırmacıdır.

Anahtar Kelimeler: Kent Paryaları, ileri marjinallik, bölgesel damgalama, kent sosyolojisi, Pierre Bourdieu

\footnotetext{
${ }^{*}$ Makalenin İngilizce aslı için bkz: Slater, T. (2017). Loïc Wacquant. Koch, R. \& Latham, A. (der.), Key Thinkers on Cities içinde (ss. 237-242). London: SAGE.
}

idealkent @ Kent Araştırmaları Dergisi (Journal of Urban Studies) 


\title{
Loïc Wacquant: Outline of a Comparative Urban Sociology
}

*

\author{
Tom Slater \\ University of Edinburgh
}

\begin{abstract}
The prolific student of two giants of social science, Pierre Bourdieu and William Julius Wilson, Lö̈ Wacquant is an interdisciplinary sociologist who has made varied and original contributions to urban studies, although his influence extends well beyond cities. His foundational writings on carnal sociology, the penal state, ethnoracial domination and social theory have been translated into two dozen languages and have triggered debates in multiple disciplines. He is best known among urbanists for his comparative analyses and conceptualization of advanced marginality and territorial stigmatization. He is also widely read for his thesis on the penalization of poverty, and his rethinking of the vexed question of the ghetto. His work is rooted in his insistence upon intensive fieldwork as an instrument of epistemological rupture and theoretical construction. Wacquant's emphasis on the role of the state as producer of marginality, the weight of symbolic structures in the production of dispossession in cities, and the need to fuse theory, ethnography and comparison has proven especially instructive and provocative.
\end{abstract}

Wacquant is Professor of Sociology at the University of California, Berkeley and a Researcher at the Centre de Européen de Sociologie et de Science Politique in Paris.

Keywords: Urban Outcasts, advanced marginality, territorial stigmatization, urban sociology, Pierre Bourdieu 


\section{Akademik Biyografi ve Araştırma Alanları}

Wacquant Fransa'nın güneyinde doğup büyüdü ve Fransa'nın önde gelen işletme okulu, École des Hautes Études Commerciales'de okumak için 1979 yılında Paris'e taşındı. Entelektüel serüveni Ocak 1981'de, kısa bir süre sonra akıl hocası ve entelektüel ilham kaynağı olacak olan Pierre Bourdieu tarafından verilen heyecan verici bir konferans ile değişti ve Wacquant, Nanterre'deki Paris Üniversitesi'nde ekonomiden sosyolojiye ve daha sonra Chapel Hill'deki Kuzey Kerolayna Üniversitesi'ne geçti. Wacquant 1985'te sosyolojide doktora yapmak için Şikago Üniversitesi'ne gitti. Orada, Amerikan şehirlerindeki ırkçı tecride dair ufuk açıcı bir çalışma olan (bkz. Wacquant ve Wilson, 1989) The Truly Disadvantaged'ın (1987) yazarı, ünlü sosyolog William Julius Wilson ile çalıştı. Wacquant, getto çalışmalarına hakim olan düşünümsellik eksikliğinden, mesafeli bakış açısından ve özellikle toplumsal örgütsüzlük varsayımı ile kentli sınıfaltına dair akademik bakış açısından rahatsız oldu. Wacquant, Wilson'un yaklaşımından ayrılarak Bourdieu'nun teori ve toplumsal araştırmaya dair yaklaşımını Amerikan gettosuna kazandırdı. Bir boks salonuna üye oldu ve Drake ve Cayton (1933 [1945]) tarafından betimlenen tarihi ‘Black Metropolis'in 1960'lar sonrası dönüşümünü yorumlayan bir etnografi yürütmeye başladı. Ardından araştırmasının odağını, 1990'larda Fransa'da ve Batı Avrupa'nın büyük bir kısminda hızla yayılan, kentlerin endüstrisizleşme ile baltalanmış çeper bölgelerinin iddia edilen 'gettolaşması' hakkındaki ahlaki paniğe karşılık olarak Atlantik ötesi bir kent marjinalliği karşılaştırmasına genişletti.

Şikago ve Paris arasındaki karşılaştırma, saha çalışması, araştırma verileri ve kurumsal karşılaştırmayı bir arada harmanlayarak iki kentsel monografi ile sonuçlandı: boksun gettoda içerden ve aşağıdan görünen bedensel etnografisi, Ruh ve Beden (2012 [2004]), ve getto'nun yukarıdan görünen makroanalitik tahlili, Kent Paryaları (2015 [2008]). Wacquant bunların yanı sıra, kentteki sembolik, toplumsal ve fiziksel uzam arasındaki ilişkiye yeniden 1şık tutan çok sayıda etkili makale yazdı. Tüm bu çalışmalar, getto, bölgesel damgalama, prekarya, etnografik metodoloji, kentsel sosyal politika ve ceza politikasıyla neoliberal devlet inşası arasındaki girift bağlar hakkında kavramsal yenilenmeyi gerekli kıldı (Bkz. Wacquant, 2002, 2009b, 2012, 2014).

\section{Temel Düşünceler}

Çoğunlukla katı bir Bourdieucü sosyolog olarak okunan Wacquant'ın kent üzerine çalışmalarında çok sayıda etki aynı potada erimiştir. Bourdieu'nün 
öğretileri epistemolojik temel ve analitik çerçeve sağlar. Fakat, Wacquant kentli 'prekarya'nın (ücretli emeğin parçalanması ve mekanın itibar kaybının yayılmasıyla istikrarsızlaşan endüstri-sonrası işçi sınıfının kırılgan fraksiyonları) akıbetini teşhis etmek ve haritalandırmak için geniş menzilli bir entelektüel kaynaktan, özellikle Engels, Durkheim, Weber, Mauss, Wittgenstein, Elias ve Goffman'dan yararlanır. Şikago Okulu'nun apolitik yoksulluk ve mekan betimlemelerinin ve ekonomi politiğin Marksist ve Weberci yorumlarının ekonomik belirlenimciliğinin hüsrana uğrattı̆̆ Wacquant'ın yaklaşımı şu şekilde nitelendirilebilir: (1) kentsel marjinalliğin biçimleri, dağıtımı ve yoğunluğunun belirlenmesinde devlet yapısı ve politikasının rolü üzerindeki ısrar (2) toplumsal ilişkilere yalnızca ayna tutmakla kalmayan dahası inşalarına yardımcı olan -üretimi ve yayılımında temel merkezleri kentler olan- sembolik sistemlerin önemi; (3) çeşitli ölçeklerdeki sembolik, toplumsal ve fiziksel uzamı karşılıklı dönüşümünü ve haritalandırılmasını izleme ve mekânın toplumsal tahakkümdeki rolünü aydınlatma çabası. Bu üçlü ilgi soyut teori ve somut etnografinin birleşimi olarak nitelendirilebilir ve marjinallik, etnisite ve ceza ağı etrafında gelişmiş kavramsal formülasyonlar üretir (Wacquant, 2014). Özellikle, ulusal ve disipliner sınırların ötesinde daha ileri araştırmalara kapı aralayan iki temel fikir öne çıkmaktadır.

Birincisi, Wacquant'ın karşılaştırmalı incelemeler neticesinde gettoyu, damgalanmış bir kategorinin ve tahsis edilmiş bir bölgenin 'karşılıklı ikili tayini' üzerinde temellenen, 'etno-1rksal bir kapatma aracı' olarak yeniden kavramsallaştırmasıdır (Wacquant, 2016a). Wacquant, üç temel vakanın karşılaştırması temelinde -Rönesans Avrupası'nda Yahudilerin sosyomekansal tecridi, Fordist endüstriyel metropolisteki siyah Amerikalılar ve Japonya'da Tokugawa dönemindeki Buraku'lar (Burakumin)- gettonun, ekonomik faydalanma ve sosyal dişlama gibi iki çelişen işlevi yerine getirmek için mekânı kullanan sosyo-örgütsel bir araç, kurumsal bir form olduğunu savunur. Gettonun kent yöneticileri tarafından hor görülmüş etnik bir kategoriden alınabilecek maddi değeri maksimum kılarken, üyeleriyle yakın teması asgari düzeye indirmek üzere oluşturulduğunu gösterir. Bunun sonucunda getto, başlıcası sakinlerine yasaklanan şehirdeki kurumların mükerreri olan bir dizi paralel kurumun (ibadet yerleri, basın, okullar, medikal klinikler, iş yerleri, sivil dernekler) oluşumu olan, ayırt edici sosyolojik özellikler gösterir. Bu kurumlar aynı anda, hakim olanların menfaatine kapatmayı gerçekleştiren bir kılıç, ve tâbi olanların karşllıklılık ve saygınlığı deneyimleyebileceği korunaklı bir alan sunan kalkan rolü oynarlar. Dolayı- 
sıyla, Wacquant'in getto tanımlaması çift yüzlüdür (janus-faced). Gettonun -gazetecilik, siyaset ve kent araştırmalarının büyük bölümünde hakim olanmaddi mahrumiyetin ve toplumsal çözülmenin mekanı biçimindeki betimlemelerine karşı, gettolaşmanın genellikle hedef nüfusun ekonomik gelişmesi, sosyal güçlenmesi ve sembolik birleşmesine dönüştüğünü gösterir. Wacquant (2016a) gettonun bu ikinci yüzünün eklemlenmesini, kent hayatındaki ve daha genel olarak kurumlardaki düşeyliğin (sömürü ve eşitsizlik) ve yataylığın (karşılıklılık ve eşitlik) dinamik uyumunu yakalama kabiliyetine sahip bir 'diyagonal sosyolojiyi' savunmak için kullanır. Wacquant'in Birleşik Devletler'deki komünal gettonun çöküşünü ve (makroekonomik dönüşüm ve devletin kemer sıkması nedeniyle ekonomik işlevden mahrum olan) hipergettoya mutasyonunu izah etmesine imkân veren, gettonun tarihsel anlam ve sosyolojik muhtevasına dair yürüttüğü ayrıntılı incelemedir. Böylesi bir [inceleme], esasında kayda değer derecede etnik çeşitlilik barındıran, paylaşılan bir aidiyet üretmede başarısız olan ve devlet tarafından derinlemesine nüfuz edilen Avrupa şehirlerinin çeperlerindeki iş̧̧i sınıfı bölgelerini ya da göçmen mahallelerini tanımlamak için, getto kavramının müphem ya da fursatçı kullanımına dair Wacquant'ın eleştirisini (Wacquant'in bu bölgelere yukarıda kavramsallaştırılan getto modelinden uzaklaştıkları için 'anti-getto' demesine yol açarak) sağlamlaştırdı.

İkincisi, Wacquant bölgesel damgalama kavramını 'mekânın lekelenmesi' (2007: 67) olarak nitelendirdiği belirginleşmeyi inceledikten sonra geliştirmiştir: Yaftalanmış mahalle hissiyatı Atlantik'in her iki tarafında belirmektedir. Fransız kent politikası yetkililerinin alt sinıf semtlerinden seslerinde iğrenme ile bahsettiklerini işitip, Paris'in dışındaki La Courneuve (ve Şikago'nun içindeki Woodlawn) sakinlerinin bu alçaltıc imgeleri içselleştirdiklerini ve/veya komşularına yakıştırdıklarını duyduktan sonra, Wacquant, Goffman ve Bourdieu'nün teorilerinden yararlanarak mekânsal utancı ve bu utancın etkilerini kavramsallaştırmaya koyuldu. Goffman'ın bir bireyi tayin edilmiş 'istenmeyen bir farklılıkla' 'normaller'den ayıran mikro düzeydeki ilişkisel damga görüşü (1963: 18) ile Bourdieu'nün (1991) sembolik iktidar (gerçekliğin temsillerini gerçeğe dönüştüren performatif kapasite) teorisiyle birleştirdi. Bourdieu merkezi olarak farklı sınıflar arasındaki sembolik mücadelelere, özellikle de otoriter failler ve kurumların kendi çıarlarına uygun bir toplumsal dünya tanımını dayatma yollarına ilgi duymaktaydı (cf. Teresa Caldeira). Wacquant bu görüşü kimliğin işaretleyicisi olarak mekân içinde ve mekân üzerine verilen mücadelelere genişletir. Bu teori harmanı, Wacquant'ın bölgesel damgalamayı, 'bu sülfürlü bölgelerde sık1- 
şıp kalanların yaşam deneyimlerinin muhtemelen tek belirgin özelliği' olarak tanımlamasına yardımcı olur (Wacquant, 2008: 169). Bu, mekânsal damganın diğer damgalama zeminlerinden özerkleşmesi nedeniyle, 21. yüzyıldaki ileri marjinalliğin ayırt edici bir özelliğidir. Wacquant, gelişmiş toplumlarda bazı gözden düşmüş bölgelerin, endüstriyel çağda metropolün örgütlü karşı-toplumu olarak algılanan itibarsız semtlerinin tersine, sınıf düzeyleri arasında nasıl yeniden ünlendiğini, ırksallaştığını, ve çözülmenin simgeleri ve taşıyıcıları olarak resmedildiğini aydınlatmaktadır. Mekânsal damganın toplumsal stratejiyi ve kimliği çeşitli ölçeklerde nasıl marjinalliği sağlamlaştıracak bir biçimde etkilediğini haritalandırmaktadır (Wacquant, 2014). Ayrıca getto terimini retorik abartma amaciyla ilerici politika müdahalesini teşvik etme umuduyla kullanan akademisyenlerin aslında mülksüzleştirilmiş mahallelerin ve böylelikle tam da incelemeleri gereken fenomenin daha fazla sembolik alçalmasına katkıda bulundukları konusunda uyarmaktadır.

Wacquant'nın kent sosyolojisi merceklerinden bakıldığında, devlet yekpare ürünler temin eden bürokratik bir bütün ya da 'piyasa başarısızlı̆̆ı' durumunda imdada yetişen bir cankurtaran değildir; daha ziyade, toplumsal ve fiziksel uzamı, ve özellikle alt sınıf mahallelerinin şeklini, yerleşimini, yapısını ve dokusunu devamlı surette biçimlendiren 'faili tabakalaştıran ve sinuflandıran' bir kuvvettir (2014: 1699). Metropolün marjinal bölgeleri, s1nıfsal ve mekânsal yapıdan aşağı doğru süzüldükleri için devletin maddi ve sembolik iktidarını bir ürünü olarak çözümlenir. İleri marjinallik, Wacquant (2008) tarafından, ücretli emeğin parçalanması, refah devletinin geri çekilmesi ve Fordist-Keynezyen dönemde işçi sınıfı mahallelerinin bir özelliği olan akrabalık ve mekan temelindeki karşılıklılığa dayalı sosyal ekonominin bükülmesiyle simgelenen, endüstri-sonrası kentlerde yükselen yoksulluk rejimi olarak nitelendirilir.

\section{Kentsel Araştırmalara Katkılar}

Wacquant tüm dünyada düzenli olarak konferanslar vermektedir ve çalışmaları akademik çevrelerin ötesine taşarak, özellikle Avrupa ve Latin Amerika'daki kamusal tartısmaları beslemek ve etkilemek üzere yayılmaktadır. Yazıları, özellikle kentsel düzenin altındaki neoliberal yeniden yapılandırmanın etkisini çalışan akademisyenler için kullanışlı olmuştur. Neoliberalizmi, (ekonomik kuralsızlaştırma, 'kısıtlayıcı çalışma refahı' ve 'genişleyen hapishane refahı' örgütsel üçlüsü dolayımıyla) (2012: 71) 'piyasayla uyumlu 
devlet inşası' olarak tanımlaması, sosyoloji ve antropolojiden kriminoloji ve planlamaya, coğrafya, hukuk ve toplum çalışmalarına kadar birçok disiplin üzerinden kent araştırmalarını etkilemiştir. Wacquant külliyatının, etnografiyi yaygın kanaatleri ve siyasi kategorileri delip geçen bir 'kopuş aracı' olarak kullanması, parçalanmış neoliberal kent manzarasını aşağıdan açığa çıkarmak için alan çalışması yürüten akademisyenleri harekete geçirmiştir. Şikago Okulu'nun (bkz. Elijah Anderson) tümevarımsal 'fikirleri sahada edin' yaklaşımının tersine, Wacquant'ın kuramın rehberlik ettiği etnografisi, şiddetli tartışmalar başlatmıştır. Wacquant (2002) 'Scrutinizing the Street'başlıklı makalesinde, çağdaş Birleşik Devletler'deki üç temel ırk ve yoksulluk etnografisini, 'halk kavrayışlarına, sıradan ahlakçlığa, resmi ideolojinin baştan çıkarmalarına ve akademik nezaket kurallarına aceleci teslimiyete dair belli bir epistemolojik duruşun' örnekleri olarak çözümler (2009b: 122). Wacquant'a göre, bu duruş bilimsel hatalara ve kentsel problemlere ilişkin yanlış politika teşhislerine yol açar ve akademinin, mucizevi neoliberal çözümlerin etkisine kapılmış devlet elitlerinin kategorilerine ve sorunlarına boyun eğmesini teşvik eder. Bekleneceği üzere, bu epistemik eleştiri Amerikalı sosyoloji kurumunun, bunu bir polemik olarak göz ardı eden geniş kesimlerince hoş karşılanmamıştır. Wacquant'ın çalışmasına yönelik olarak tekrarlanan diğer eleştiri, kentsel mekânı bölen temel ilkenin ve Fransız ve Avrupa metropollerinin alt sınıf mahallelerindeki yaşam şansının belirleyicisinin etnisite ya da din değil, sınıf olduğu konusundaki ısrarıdır. Schneider (2014), Wacquant'ın siyah ve Arap gençlerin bu mahallelerde yoğunlaşmasına yeterli dikkati göstermediğini savunur ve bu gençlerin, şayet ırk ayrımcllığının, ırkçı fişlemenin ve polis şiddetinin olmadığı bir toplumda yaşıyorlarsa, mahallelerini ateşe vermelerine neyin yol açtığını sorar. Wacquant'ın (2016b) cevabı, sınıfın önceliğinin, küçük fakat mekânsal olarak mobil olan post-kolonyal bir küçük burjuvazinin yükselişinin ve yabancı ve ulusal nüfusların demografik profilindeki her yerde artan benzerliğin gösterdiği ampirik bir olgu olduğudur.

Wacquant'nın kent çalışmalarına en önemli katkısı, kentteki marjinalliğin üretilmesinde sembolik yapıların oynadığı rolün göz ardı edilmesinin, yoksulluğun altında yatan sorunların ifadesi olarak mahalle kavrayışından, yoksulluğun gerekçesi olarak mahalle kavrayışına geçişle neticelendiğini göstermesidir. Mahallenin etkileri hakkındaki, birinin yaşadığı yerin o kişinin yaşam şansını etkilediği yönündeki önermeye dayanan geniş literatür, mekânsal damgalamanın mekanizmalarını ve sonuçlarını göz ardı eder. Esasen bu literatür birçok durumda, tam da marjinalleşmiş mahalleler üze- 
rinde eğitimli bir küçültücü bakış aracılığıyla damgalamayı perçinler. Wacquant'ın çalışması sosyal bilimlerin bu bakışı boşa çıkarmada ve hastalığı ya da 1stırabı ifade ettiği kadar maskeleyen, 'çoğu kez saçma, kimi zaman tiksindirici öngörülerin perdesinin delinip geçilmesinde' (Bourdieu, 1999: 629) oynayacağı bir role sahip olduğunu göstermektedir.

\section{Kaynakça/References}

\section{İkincil Kaynaklar ve Referanslar}

Bourdieu, P. (1991). Language and symbolic power. Cambridge: Polity Press.

Bourdieu, P. (1999). The weight of the world: Social suffering in contemporary society. Cambridge: Polity Press.

Drake, S. and Cayton, H. (1993 [1945]). Black metropolis: A study of negro life in a northern city. Chicago: University of Chicago Press.

Goffman, E. (1963). Stigma: notes on the management of spoiled identity. London: Penguin.

Schneider, C.L. (2014). Police power and race riots: Urban unrest in Paris and New York. Philadelphia: University of Pennsylvania Press.

Wacquant, L. (2009b). The body, the ghetto and the penal state. Qualitative Sociology, 32(1): 101-129.

Wacquant, L. (2012). Three steps to a historical anthropology of actually existing neoliberalism. Social Anthropology, 20(1): 66-79.

Wacquant, L. (2014). Marginality, ethnicity and penality in the neoliberal city: An analytic cartography. Ethnic and Racial Studies, 37(10): 1687-1711.

Wacquant, L. (2016b). Revisiting territories of relegation: Class, ethnicity and the state in the making of marginality. Urban Studies, 53(6): 1077-1088.

Wacquant, L. and Wilson, W.J. (1989). The cost of racial and class exclusion in the inner city. Annals of the American Academy of Political and Social Science, 501: 8-25.

\section{Temel kent yazıları}

Wacquant, L. (2002). Scrutinizing the street: Poverty, morality and the pitfalls of urban ethnography. American Journal of Sociology, 107(6): 1468-1532.

Wacquant, L. (2004). Body and soul: Notebooks of an apprentice boxer. New York and Oxford: Oxford University Press.

Wacquant, L. (2008). Urban outcasts: A comparative sociology of advanced marginality. Cambridge: Polity Press.

Wacquant, L. (2009a). Punishing the poor: The neoliberal government of social insecurity. Durham, NC and London: Duke University Press.

Wacquant, L. (2016a). The two faces of the ghetto. New York: Oxford University Press.

Tom Slater Edinburgh Üniversitesi Kentsel Coğrafya Bölümü'nde profesördür. Temel ilgi alanları, kentsel soylulaştırma, yerinden edilme ve bölgesel damgalamadır.

Tom Slater is a professor of Urban Geography at the University of Edinburgh. His studies focus on gentrification, displacement, and territorial stigmatization. 